\title{
The Role of Mathematical and Trait Anxiety in Mental Fatigue: an EEG Investigation
}

\author{
Ekaterina S. Zhban ${ }^{\star a}$, Maxim V. Likhanov ${ }^{\mathrm{b}}$, Ilya M. Zakharov ${ }^{\mathrm{c}}$, \\ Elizaveta M. Bezrukova a , Sergey B. Malykh ${ }^{c}$ \\ a International Centre for Research in Human Development, Tomsk State University, Tomsk, Russia \\ ${ }^{\mathrm{b}}$ Educational Fund "Talent and success", Centre "Sirius", Sochi, Russia \\ c Psychological Institute, Russian Academy of Education, Russia \\ *Corresponding author. E-mail: z.katherina@gmail.com
}

Background. Mental fatigue is a state of tiredness, decreased motivation, and increased aversion to performing a task. Mental fatigue is associated with the length of engagement in an activity (time-on-task) and the degree of cognitive effort required. In addition, mental fatigue can be affected by personality characteristics, such as trait or domain-specific anxiety. There is a lack of research into associations between mental fatigue and trait anxiety, as well as specific types of anxiety such as math anxiety.

Objective. This study investigates whether the level of mental fatigue manifested in an EEG taken during the performance of a mixed problem-solving task, is associated with math and trait anxiety.

Design. An EEG recording was performed on participants in a resting state with their eyes closed in two runs, both before and after they performed a task. The task consisted of three types of stimuli: arithmetic, algebraic, and lexical.

Results. The results showed that the EEG correlates of fatigue changed between the first and second runs. These changes were not linked with mathematics anxiety. Some significant EEG effects were found for trait anxiety: people with high trait anxiety appeared more aroused and showed less fatigue effects. However, these results did not reach the level of significance after correction for multiple comparisons.

Conclusion. Overall, our results are in line with the motivational control theory, according to which mental fatigue "resets" when a person switches from one task to another. In our study, the experimental paradigm consisted of three types of tasks, a format which might have prevented fatigue. We discuss the implications of the study for further research into the links between anxiety and mental fatigue.

Keywords: Mathematics anxiety (MA), trait anxiety (TA), EEG, mental fatigue 


\section{Introduction}

Mental fatigue is a state that generally manifests itself as tiredness, decreased motivation, and aversion to perform a task (Boksem \& Tops, 2008; Matthews, Desmond, \& Hitchcock, 2012). It develops as a function of the time-on-task and depends on the amount of cognitive effort required (Boksem, Meijman, \& Lorist, 2005; Lorist et al., 2000). Mental fatigue can be operationalized by various methods, including neuroimaging. Craig and colleagues (2012) reviewed 17 experimental papers where mental fatigue was measured by changes in the spectral power of different EEG bands. According to this review, theta, beta, and alpha band activity and their ratios are likely to increase with the increase of mental fatigue.

The relationships between mental fatigue, time-on-task, and cognitive effort are not always linear. Studies show that people differ in their vulnerability to mental fatigue: Some people can continue their work for a long time without any effects on their performance, while others start showing the signs of fatigue very early (Matthews et al., 2012). Fatigue is frequently connected with sleep loss, circadian rhythms, and health issues. However, it is also linked to personality traits, such as introversion, neuroticism, sensitivity to punishment, behavioral inhibition, and anxiety (Matthews et al., 2012). Here we focus on the association between mental fatigue and two types of anxiety-trait and math anxiety.

A link between mental fatigue and trait anxiety (TA) was previously reported by several studies; it was shown to range from 0.28 to 0.59 (Craig, Tran, Wijesuriya, \& Boord, 2006; Jiang et al., 2003; Wijesuriya, Tran, \& Craig, 2007). The classical view of mental fatigue explains the phenomenon as "a lack of sufficient steady state energy to power ... cognitive work" (Hancock, Desmond, \& Matthews, 2012, p. 67). If this is the case, then this link between mental fatigue and trait anxiety can be explained by an increased need for resources by people with high anxiety, which is suggested by the Processing Efficiency Theory (PET; Eysenck \& Calvo, 1992) and Attentional Control Theory (ACT; Eysenck, Derakshan, Santos, \& Calvo, 2007). These two theories are generally used to interpret the mechanisms of anxiety's effects on performance.

The PET assumes that anxiety reduces the working memory capacity available for task processing, as engagement in an anxiety-related task causes people to experience stress and intrusive thoughts, and to ruminate on these intrusive thoughts. The ACT extends PET, and postulates that anxiety in general affects the ability to allocate attentional and cognitive resources to task performance. Due to an impaired inhibitory function, anxious people become more distracted by task-irrelevant stimuli, regardless of whether these stimuli are external (i.e., conventional distractors) or internal (i.e., worrying thoughts, ruminations, etc.).

In summary, researchers concur that people with high trait anxiety not only need resources for task processing, but also resources to deal with anxiety-induced thoughts and to inhibit distracting stimuli. This assumption is confirmed by multiple studies which showed that people with trait anxiety perform more poorly than non-anxious people under stressful conditions, especially in ego-threatening conditions, such as when they are being observed by other people (Edwards, Edwards, \& Lyvers, 2017; Rezaei, Hosseini Ramaghani, \& Fazio, 2017). Based on the classic interpretation of mental fatigue, this double requirement for resources may make anxious people more vulnerable to mental fatigue. 
The PET and ACT framework has also been applied to maths anxiety (MA) (Carretié, Mercado, Tapia, \& Hinojosa, 2001; Núñez-Peña \& Suárez-Pellicioni, 2014; Wang, Huang, Ma, \& Li, 2012). Maths anxiety is defined as "a feeling of tension and anxiety that interferes with the manipulation of numbers and solving of mathematical problems in ... ordinary life and academic situations" (Richardson \& Suinn, 1972). MA has been shown to play a role in underperformance in mathematics (Artemenko, Daroczy, \& Nuerk, 2015; Suárez-Pellicioni, Núñez-Peña, \& Colomé, 2016). Research has shown that MA correlates with TA $(r=0.35)$. However, MA cannot be viewed as an expression of TA, since different aspects of MA correlate more highly with one another (0.5-0.8) than with TA (Dowker, Sarkar, \& Looi, 2016).

The present study employs the EEG method to explore links between TA, MA, and mental fatigue. Mental fatigue is measured as an increase in theta, alpha, and beta band activity during rest conditions in the course of a cognitive task (Craig, Tran, Wijesuriya, \& Nguyen, 2012). We chose a resting state condition because previous studies have demonstrated that electrical brain activity during a resting state might be related to psychological states and emotional regulation processes (Knyazev, 2007; Putman, 2011). Based on previous research, we hypothesized that mental fatigue would positively correlate with TA. We also hypothesised a positive correlation between mental fatigue and MA, as similar mechanisms may be involved in the association between fatigue and all types of anxiety.

\section{Methods \\ Objective}

The aim of the present study is to investigate whether the level of mental fatigue, manifested in EEG activity, is associated with math and trait anxiety.

\section{Participants}

All participants were tested at one of the two research centers in Russia. Participants were recruited via social media, as part of an ongoing twin study (Kovas et al., 2013). Two hundred twenty-five participants, including 61 singletons and 82 pairs of twins, took part in the study. Only one twin from each pair was randomly selected, in order to account for twin non-independence (Rijsdijk \& Sham, 2002). After the exclusion of participants with missing EEG recordings, the final sample (singletons and one twin from a pair) included 101 participants with mean age of 21.62 ( $\mathrm{SD}=4.28$; 33 males, 68 females). All participants were native Russian speakers, and had normal or corrected-to-normal vision and no history of head injury, neurological or psychiatric disorder. Participants gave their informed written consent prior to the experiment. The study was approved by the Ethical Committee for Interdisciplinary Investigations (Tomsk State University).

\section{Design and experimental procedure}

Demographic, psychological, and physiological (EEG) data were collected. Participants were requested to fill in a demographic questionnaire that included information about their age and sex. They then completed psychological inventories and the EEG experiment. 
Math anxiety. Math anxiety was measured with the Shortened Math Anxiety Rating Scale (sMARS; Alexander \& Martray, 1989). This test measures math anxiety by presenting participants with 25 math-related situations. Participants rated, on a 5-point Likert scale, how much anxiety they experienced in each particular situation. A 21-item Russian adaptation of sMARS was used, which has four items removed from the questionnaire based on their poor psychometric properties (see Likhanov et al., 2017). As in previous research (Ashcraft \& Moore, 2009), the total score of all items (21 in this study) was used as a singular measure of math anxiety.

Trait anxiety. The level of trait anxiety was measured with a Russian adaptation of the Spielberger Trait Anxiety Questionnaire (Spielberger, 1989; Hanin, 1983). The questionnaire consists of 20 questions on how anxious participants feel in their ordinary life on a 4-point Likert scale. The trait anxiety score was calculated as a simple sum of scores, without applying any coefficients.

EEG recording. Participants were instructed to sit comfortably and try not to move their eyes. The recording was made in a dimly lit, soundproof, and electromagnetically shielded room. The resting state data were recorded two times: before and after the main EEG data collection session, which on average lasted for 90 minutes. Each resting state recording run included five two-minute series with closed and open eyes (10 minutes), which were recorded in the following order: eyes closed - eyes open - eyes closed - eyes open - eyes closed; four minutes with open and six minutes with closed eyes in total. Only the data in the eyes-closed condition was used for further analysis. The resting state after the main session included four two-minute series: eyes closed - eyes open - eyes closed - eyes open (eight minutes in total).

During the main session, participants were to complete three types of problemsolving tasks: lexical, algebraic, and arithmetic. There were 70 trials of each task type, with 35 correct and 35 incorrect trials in each task, all of which were completely randomized (see Bloniewski, Likhanov et al., 2018).

The data were collected with the BrainVision PyCorder software (Brain Products). The EEG data were recorded from the scalp using 64 channels (63 EEG + VEOG) via Ag/AgCl electrodes placed according to the international 10-20 system. The EEG data were recorded without online filtering, with the sampling rate of 500 $\mathrm{Hz}$. The $\mathrm{Cz}$ electrode was used as a reference, and the $\mathrm{FPz}$ was used as a ground. The data were then preprocessed offline using BrainVision Analyzer 2. The recorded data were downsampled to $256 \mathrm{~Hz}$ and filtered with a $0.1-40 \mathrm{~Hz}$ filter.

The data were then re-referenced to an averaged reference and manually cleaned from artifacts, with noisy channels excluded. To remove blink and vertical eye-movement artifacts, independent component analysis (ICA) was performed on the following electrodes: VEOG - AFz, HEOG - FT9, and FT10. After ICA, the excluded channels were topographically interpolated, and semiautomatic artifact rejection was conducted. Fast Fourier transformation (FFT) was applied to $2 \mathrm{~s}$ artifact-free epochs at every channel to extract spectral power values of the signal 
in selected frequency bands (alpha, theta, and beta). The FFT results were averaged across at least 150 epochs for each channel.

In this study the changes in spectral power were investigated at seven electrodes: Fz, F3, F4, F7, F8, Cz and Pz. The rationale was that the effects of mental fatigue tend to gravitate towards midline and frontal electrodes in theta rhythm (Strijkstra, Beersma, Drayer, Halbesma, \& Daan, 2003; Wascher et al., 2014); frontocentral and parietal regions for alpha (Cantero, Atienza, Salas, \& Gómez, 1999; Oken, Salinsky, \& Elsas, 2006; Santamaria \& Chiappa, 1987), and frontal regions for the beta spectral band (Craig et al., 2012).

Mental fatigue measures. The following EEG bands were used: alpha (8-12 Hz), beta $(12-30 \mathrm{~Hz})$, and theta $(4-7 \mathrm{~Hz})$. We estimated absolute spectral power in selected frequency bands. Relative power was also used in the present study as a more reliable measure of spectral power (Nuwer, 1988) and was computed as follows:

1. relative alpha spectral power $=$ alpha spectral power $/$ (alpha spectral power + theta spectral power + beta spectral power)

2. relative theta spectral power $=$ theta spectral power $/($ alpha spectral power + theta spectral power + beta spectral power)

3. relative beta spectral power $=$ beta spectral power /(alpha spectral power + theta spectral power + beta spectral power)

An increase in theta, alpha, and beta band activity indicates an increase in mental fatigue (Cheng \& Hsu, 2011; Craig et al., 2012; Eoh, Chung, \& Kim, 2005).

We also used two composite measures, which have been shown to correlate with fatigue. First, we used the Task Load Index (TLI), which reflects the degree of neural activation during effortful task performance (Gevins \& Smith, 2003). TLI is calculated as the ratio of theta activity at frontal midline sites, to alpha at parietal sites (here as theta at $\mathrm{Fz}$ to alpha at $\mathrm{Pz}$ ). It is expected to increase with the development of mental fatigue (Cheng \& Hsu, 2011; Kamzanova, Matthews, Kustubayeva, \& Jakupov, 2011). Second, we used the Relative Energy Index (REI), which has been shown to correlate positively with an increase in mental fatigue, as fatigue is expected to increase with a decrease of energy (Cheng \& Hsu, 2011; Eoh et al., 2005). REI is calculated as ratio of (alpha + theta) to beta activity.

To reduce the number of statistical comparisons, in this study mental fatigue was estimated as the difference in spectral power between run one and run two the difference score. The difference score was estimated for each frequency band and the two coefficients (TLI and REI). The difference score was also used in a correlational analysis, to explore the link between mental fatigue and anxiety.

Mental fatigue may be related to a participant's state, e.g. how fatigued one already is prior to the experiment. Therefore, we calculated partial correlations between math and trait anxiety and the difference score for all parameters at all electrodes, controlling for EEG spectral power in run one. Partial correlations were computed between the two types of anxieties and both absolute and relative power values. The false-discovery rate (FDR) was applied as a correction for multiple comparisons. 


\section{Results}

First, we tested whether the changes in mean spectral power for all ranges and spectral ratios, which occurred between run one and run two in the regions of interest, were associated with mental fatigue. We used a non-parametric Wilcoxon signed-rank test as an assumption of the normality of the mean difference between spectral power in alpha, theta, and beta ranges, and spectral ratios in run one and run two were violated for most of the electrodes. The analysis showed that absolute band power increased significantly at all electrodes in all bands (see Table 1). The relative band power before and after performing the task was significantly different for all electrodes for alpha (decreased) and theta (increased) bands, but not for the beta band (see Table 2). The spectral ratios (TLI and REI) did not change significantly (see Table 3).

Table 1

Descriptive statistics and Wilcoxon Signed Rank Tests for absolute activity

\begin{tabular}{|c|c|c|c|c|c|c|c|}
\hline $\begin{array}{l}\text { Power } \\
\text { band }\end{array}$ & $\begin{array}{l}\text { Elect- } \\
\text { rode }\end{array}$ & $\begin{array}{l}\text { Mean }(S D) \\
\text { for run } 1\end{array}$ & $\begin{array}{c}\text { Mean (SD) } \\
\text { for run } 2\end{array}$ & $\begin{array}{l}\text { Mean (SD)for } \\
\text { difference score }\end{array}$ & $Z$ & $\begin{array}{c}p- \\
\text { value }\end{array}$ & $\begin{array}{c}\text { Effect } \\
\text { size }\end{array}$ \\
\hline \multirow[t]{7}{*}{ Alpha } & $\mathrm{Fz}$ & $0.57(0.26)$ & $0.62(0.30)$ & $0.05(0.30)$ & -2.27 & .01 & 0.23 \\
\hline & F3 & $0.55(0.24)$ & $0.60(0.26)$ & $0.06(0.24)$ & -3.14 & .00 & 0.32 \\
\hline & $\mathrm{F} 4$ & $0.57(0.28)$ & $0.58(0.25)$ & $0.18(0.75)$ & -1.75 & .04 & 0.18 \\
\hline & F7 & $0.67(0.42)$ & $0.84(0.67)$ & $0.02(0.30)$ & -4.20 & .00 & 0.42 \\
\hline & F8 & $0.64(0.38)$ & $0.79(0.76)$ & $0.14(0.83)$ & -3.36 & .00 & 0.34 \\
\hline & $\mathrm{Cz}$ & $0.48(0.23)$ & $0.54(0.38)$ & $0.07(0.41)$ & -2.54 & .01 & 0.25 \\
\hline & $\mathrm{Pz}$ & $0.67(0.37)$ & $0.73(0.48)$ & $0.08(0.39)$ & -2.28 & .01 & 0.23 \\
\hline \multirow[t]{7}{*}{ Beta } & $\mathrm{Fz}$ & $0.26(0.13)$ & $0.31(0.20)$ & $0.09(0.24)$ & -4.89 & .00 & 0.49 \\
\hline & F3 & $0.28(0.13)$ & $0.34(0.16)$ & $0.10(0.16)$ & -5.44 & .00 & 0.55 \\
\hline & $\mathrm{F} 4$ & $0.29(0.20)$ & $0.32(0.12)$ & $0.19(0.81)$ & -4.96 & .00 & 0.50 \\
\hline & F7 & $0.42(0.35)$ & $0.57(0.64)$ & $0.06(0.25)$ & -5.30 & .00 & 0.53 \\
\hline & F8 & $0.38(0.34)$ & $0.53(0.73)$ & $0.18(0.85)$ & -5.69 & .00 & 0.57 \\
\hline & $\mathrm{Cz}$ & $0.24(0.16)$ & $0.30(0.40)$ & $0.1(0.48)$ & -4.55 & .00 & 0.46 \\
\hline & $\mathrm{Pz}$ & $0.28(0.19)$ & $0.34(0.25)$ & $0.10(0.34)$ & -4.40 & .00 & 0.44 \\
\hline \multirow[t]{7}{*}{ Theta } & $\mathrm{Fz}$ & $0.46(0.46)$ & $0.56(0.27)$ & $0.11(0.64)$ & -4.67 & .00 & 0.47 \\
\hline & F3 & $0.43(0.21)$ & $0.53(0.22)$ & $0.16(1.02)$ & -5.84 & .00 & 0.59 \\
\hline & $\mathrm{F} 4$ & $0.45(0.24)$ & $0.51(0.19)$ & $0.20(0.89)$ & -4.55 & .00 & 0.46 \\
\hline & F7 & $0.60(0.46)$ & $0.80(0.69)$ & $0.16(1.37)$ & -5.55 & .00 & 0.56 \\
\hline & F8 & $0.54(0.38)$ & $0.74(0.77)$ & $0.21(1.11)$ & -5.71 & .00 & 0.57 \\
\hline & $\mathrm{Cz}$ & $0.40(0.19)$ & $0.50(0.45)$ & $0.15(0.94)$ & -3.93 & .00 & 0.40 \\
\hline & $\mathrm{Pz}$ & $0.47(0.31)$ & $0.57(0.48)$ & $0.17(1.07)$ & -4.00 & .00 & 0.40 \\
\hline
\end{tabular}

Note. $p<.05$ is counted as significant. 
Table 2

Descriptive statistics and Wilcoxon Signed Rank Tests for relative activity

\begin{tabular}{|c|c|c|c|c|c|c|c|}
\hline $\begin{array}{l}\text { Power } \\
\text { band }\end{array}$ & $\begin{array}{l}\text { Elect- } \\
\text { rode }\end{array}$ & $\begin{array}{c}\text { Mean (SD) } \\
\text { for run } 1\end{array}$ & $\begin{array}{c}\text { Mean (SD) } \\
\text { for run } 2\end{array}$ & $\begin{array}{l}\text { Mean (SD) for } \\
\text { difference score }\end{array}$ & $\mathbf{z}$ & $\begin{array}{c}p- \\
\text { value }\end{array}$ & $\begin{array}{c}\text { Effect } \\
\text { size }\end{array}$ \\
\hline \multirow[t]{7}{*}{ Alpha } & $\mathrm{Fz}$ & $0.43(0.08)$ & $0.41(0.08)$ & $-0.02(0.06)$ & -2.45 & .01 & 0.25 \\
\hline & F3 & $0.43(0.08)$ & $0.4(0.07)$ & $-0.02(0.06)$ & -3.04 & .00 & 0.31 \\
\hline & $\mathrm{F} 4$ & $0.43(0.07)$ & $0.4(0.07)$ & $-0.01(0.06)$ & -3.13 & .00 & 0.31 \\
\hline & F7 & $0.40(0.06)$ & $0.39(0.06)$ & $-0.02(0.06)$ & -2.3 & .01 & 0.23 \\
\hline & F8 & $0.41(0.07)$ & $0.39(0.07)$ & $-0.02(0.06)$ & -3.26 & .00 & 0.33 \\
\hline & $\mathrm{Cz}$ & $0.43(0.07)$ & $0.41(0.07)$ & $-0.02(0.06)$ & -2.19 & .01 & 0.22 \\
\hline & $\mathrm{Pz}$ & $0.47(0.09)$ & $0.44(0.08)$ & $-0.02(0.07)$ & -2.57 & .01 & 0.26 \\
\hline \multirow[t]{7}{*}{ Beta } & $\mathrm{Fz}$ & $0.20(0.04)$ & $0.21(0.04)$ & $0.01(0.04)$ & -1.3 & .1 & 0.13 \\
\hline & F3 & $0.23(0.05)$ & $0.23(0.04)$ & $0.00(0.04)$ & 0.52 & .7 & 0.05 \\
\hline & $\mathrm{F} 4$ & $0.22(0.05)$ & $0.23(0.04)$ & $0.00(0.04)$ & -0.66 & .26 & 0.07 \\
\hline & F7 & $0.25(0.05)$ & $0.25(0.05)$ & $0.00(0.04)$ & 0.48 & .68 & 0.05 \\
\hline & F8 & $0.24(0.05)$ & $0.25(0.04)$ & $0.01(0.04)$ & -0.83 & .2 & 0.08 \\
\hline & $\mathrm{Cz}$ & $0.21(0.04)$ & $0.21(0.04)$ & $0.00(0.04)$ & -0.41 & .34 & 0.04 \\
\hline & $\mathrm{Pz}$ & $0.20(0.05)$ & $0.21(0.04)$ & $0.01(0.04)$ & -0.84 & .2 & 0.08 \\
\hline \multirow[t]{7}{*}{ Theta } & $\mathrm{Fz}$ & $0.36(0.07)$ & $0.38(0.07)$ & $0.01(0.04)$ & -2.37 & .01 & 0.24 \\
\hline & F3 & $0.35(0.07)$ & $0.37(0.07)$ & $0.02(0.04)$ & -3.76 & .00 & 0.38 \\
\hline & $\mathrm{F} 4$ & $0.35(0.07)$ & $0.37(0.07)$ & $0.01(0.06)$ & -3.37 & .00 & 0.34 \\
\hline & F7 & $0.35(0.06)$ & $0.36(0.07)$ & $0.02(0.04)$ & -2.29 & .01 & 0.23 \\
\hline & F8 & $0.35(0.06)$ & $0.36(0.06)$ & $0.02(0.05)$ & -3.3 & .00 & 0.33 \\
\hline & $\mathrm{Cz}$ & $0.37(0.06)$ & $0.38(0.07)$ & $0.01(0.04)$ & -1.6 & .05 & 0.16 \\
\hline & $\mathrm{Pz}$ & $0.33(0.08)$ & $0.35(0.07)$ & $0.01(0.05)$ & -2.61 & .00 & 0.26 \\
\hline
\end{tabular}

Note. $p<.05$ is counted as significant.

Significant differences between the two runs were considered to manifest mental fatigue. To reduce the number of statistical comparisons, we calculated the difference scores by subtracting the spectral power at run two from that at run one separately for each frequency band (See Figure 1). For the bands that were significantly different, we were interested whether the difference scores for absolute and relative spectral power characteristics correlated with math and trait anxiety. 
Table 3

Descriptive statistics and Wilcoxon Signed Rank Tests for spectral ratios difference score

\begin{tabular}{cccccccc}
\hline $\begin{array}{c}\text { Power } \\
\text { band }\end{array}$ & $\begin{array}{c}\text { Elec- } \\
\text { trode }\end{array}$ & $\begin{array}{c}\text { Mean (SD) } \\
\text { for run 1 }\end{array}$ & $\begin{array}{c}\text { Mean (SD) } \\
\text { for run 2 }\end{array}$ & $\begin{array}{c}\text { Mean (SD) for dif- } \\
\text { ference score }\end{array}$ & $\boldsymbol{z}$ & $\begin{array}{c}\boldsymbol{p} \text { - } \\
\text { value }\end{array}$ & $\begin{array}{c}\text { Effect } \\
\text { size }\end{array}$ \\
\hline \multirow{2}{*}{$\mathrm{REI}$} & $\mathrm{Fz}$ & $4.17(1.15)$ & $3.96(1.03)$ & $-0.18(0.94)$ & -1.25 & .11 & 0.13 \\
& $\mathrm{~F} 3$ & $3.65(1.07)$ & $3.54(0.92)$ & $-0.09(0.83)$ & 0.04 & .52 & 0 \\
& $\mathrm{~F} 4$ & $3.22(0.86)$ & $3.17(0.82)$ & $-0.14(0.82)$ & 0.09 & .54 & 0.01 \\
& $\mathrm{~F} 7$ & $3.73(1.07)$ & $3.57(0.92)$ & $-0.03(0.77)$ & -0.8 & .21 & 0.08 \\
& $\mathrm{~F} 8$ & $3.34(0.90)$ & $3.18(0.75)$ & $-0.16(0.81)$ & -1.03 & .15 & 0.1 \\
& $\mathrm{Cz}$ & $4.01(1.01)$ & $3.89(0.91)$ & $-0.13(0.85)$ & -0.62 & .27 & 0.06 \\
& $\mathrm{Pz}$ & $4.23(1.22)$ & $3.99(1.02)$ & $-0.20(1.04)$ & -1.09 & .14 & 0.11 \\
$\mathrm{TLI}$ & & $0.88(0.66)$ & $0.95(0.53)$ & $0.04(0.54)$ & -0.42 & .34 & 0.04 \\
\hline
\end{tabular}

Note. $p<.05$ is counted as significant.

1 Absolute power

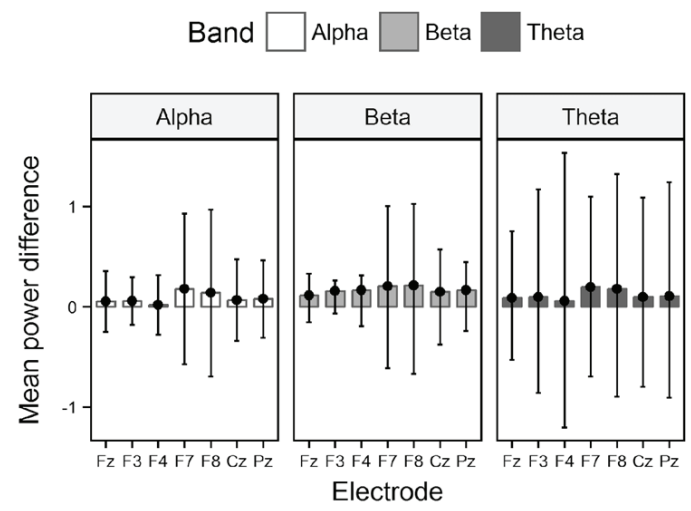

3 Composite measures

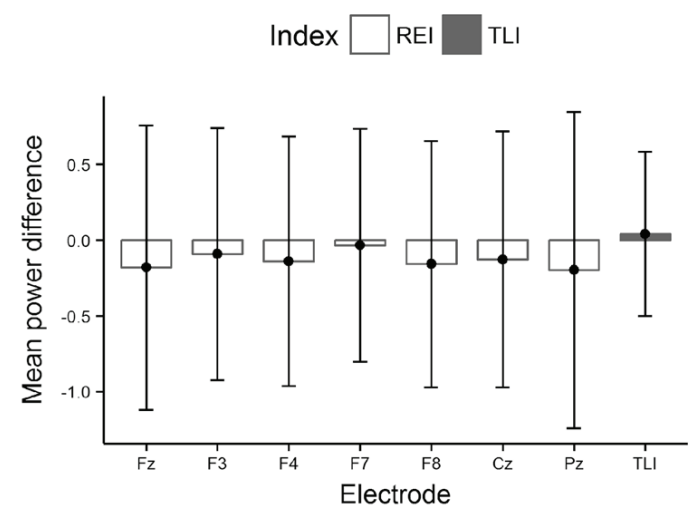

2 Relative power

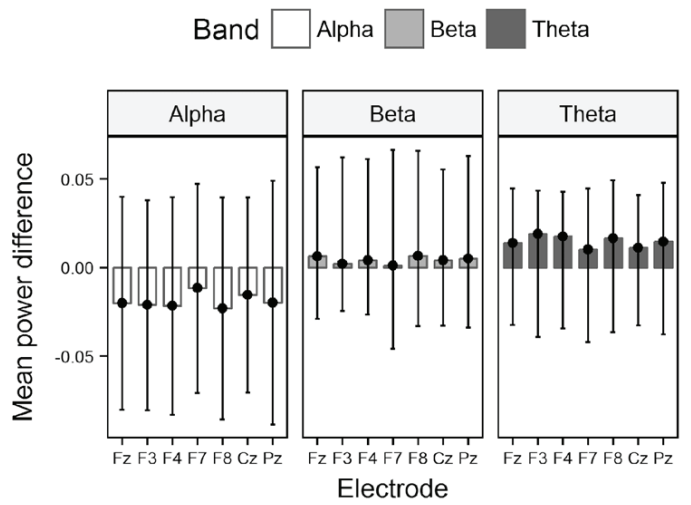

Figure 1. Deviation bar graphs for EEG power difference scores from run one to run two. 1. Absolute power difference; 2 . Relative power difference; 3 . Power difference for the two composite measures (REI and TLI). 
Table 4

Correlations between EEG power difference score and math and trait anxiety

\begin{tabular}{|c|c|c|c|c|c|c|c|c|}
\hline & & & & Math any & & & Trait any & \\
\hline Pow & r band & Electrode & Rho & $p$-value & $\begin{array}{c}p \text { FDR } \\
\text { adjusted }\end{array}$ & Rho & $p$-value & $\begin{array}{c}p \text { FDR } \\
\text { adjusted }\end{array}$ \\
\hline & Alpha & $\mathrm{Fz}$ & 0.06 & .55 & .98 & 0.07 & .54 & .7 \\
\hline & & F3 & 0.11 & .29 & .98 & 0.08 & .49 & .7 \\
\hline & & $\mathrm{F} 4$ & 0.02 & .81 & .98 & 0.03 & .76 & .86 \\
\hline & & F7 & 0.0 & .98 & .98 & 0.1 & .36 & .7 \\
\hline & & F8 & -0.15 & .16 & .98 & 0.17 & .11 & .28 \\
\hline & & $\mathrm{Cz}$ & -0.02 & .87 & .98 & 0.1 & .36 & .7 \\
\hline & & $\mathrm{Pz}$ & 0.14 & .17 & .98 & 0.0 & .98 & .99 \\
\hline & Beta & $\mathrm{Fz}$ & 0.03 & .75 & .98 & -0.17 & .11 & .28 \\
\hline & & F3 & 0.02 & .88 & .98 & -0.07 & .53 & .7 \\
\hline & & $\mathrm{F} 4$ & -0.04 & .68 & .98 & -0.08 & .44 & .7 \\
\hline כె & & F7 & -0.08 & .46 & .98 & -0.05 & .67 & .8 \\
\hline \& & & F8 & -0.08 & .45 & .98 & -0.08 & .45 & .7 \\
\hline & & $\mathrm{Cz}$ & -0.02 & .87 & .98 & 0.08 & .45 & .7 \\
\hline & & $\mathrm{Pz}$ & 0.1 & .33 & .98 & -0.03 & .81 & .89 \\
\hline & Theta & $\mathrm{Fz}$ & 0.03 & .8 & .98 & -0.06 & .59 & .74 \\
\hline & & F3 & -0.01 & .9 & .98 & 0.0 & .99 & .99 \\
\hline & & $\mathrm{F} 4$ & -0.09 & .41 & .98 & -0.07 & .53 & .7 \\
\hline & & F7 & -0.06 & .57 & .98 & 0.0 & .99 & .99 \\
\hline & & F8 & -0.16 & .12 & .98 & 0.04 & .69 & .8 \\
\hline & & $\mathrm{Cz}$ & -0.06 & .55 & .98 & 0.11 & .31 & .7 \\
\hline & & $\mathrm{Pz}$ & 0.13 & .23 & .98 & -0.07 & .53 & .7 \\
\hline & Alpha & $\mathrm{Fz}$ & 0.05 & .66 & .98 & 0.26 & .02 & .15 \\
\hline & & F3 & 0.06 & .54 & .98 & 0.2 & .06 & .19 \\
\hline & & F4 & 0.09 & .4 & .98 & 0.22 & .04 & .15 \\
\hline & & F7 & 0.03 & .77 & .98 & 0.24 & .02 & .15 \\
\hline & & F8 & -0.07 & .54 & .98 & 0.29 & .01 & .15 \\
\hline & & $\mathrm{Cz}$ & -0.01 & .96 & .98 & 0.09 & .38 & .7 \\
\hline 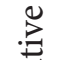 & & $\mathrm{Pz}$ & 0.01 & .89 & .98 & 0.11 & .33 & .7 \\
\hline$\frac{\pi}{2}$ & Theta & $\mathrm{Fz}$ & -0.05 & .63 & .98 & -0.22 & .04 & .15 \\
\hline & & F3 & -0.04 & .72 & .98 & -0.23 & .03 & .15 \\
\hline & & $\mathrm{F} 4$ & -0.09 & .39 & .98 & -0.22 & .04 & .15 \\
\hline & & F7 & -0.04 & .68 & .98 & -0.22 & .04 & .15 \\
\hline & & F8 & -0.06 & .55 & .98 & -0.23 & .03 & .15 \\
\hline & & $\mathrm{Cz}$ & 0.0 & .96 & .98 & -0.18 & .09 & .26 \\
\hline & & $\mathrm{Pz}$ & 0.04 & .69 & .98 & -0.22 & .04 & .15 \\
\hline
\end{tabular}

Note. $p<.05$ is counted as significant. 
Table 5

Partial correlations between EEG power difference score and mats and trait anxiety

\begin{tabular}{|c|c|c|c|c|c|c|c|}
\hline \multirow[b]{2}{*}{ Power band } & \multirow[b]{2}{*}{ Electrode } & \multicolumn{3}{|c|}{ Math anxiety } & \multicolumn{3}{|c|}{ Trait anxiety } \\
\hline & & Rho & $p$-value & $\begin{array}{c}p \text { FDR } \\
\text { adjusted }\end{array}$ & Rho & $p$-value & $\begin{array}{c}p \text { FDR } \\
\text { adjusted }\end{array}$ \\
\hline \multirow[t]{7}{*}{ Alpha } & $\mathrm{Fz}$ & 0.07 & .48 & .97 & 0.05 & .64 & .97 \\
\hline & F3 & 0.13 & .21 & .97 & 0.05 & .67 & .97 \\
\hline & F4 & 0.06 & .56 & .97 & -0.00 & .99 & .97 \\
\hline & F7 & 0.04 & .67 & .97 & 0.07 & .51 & .97 \\
\hline & F8 & -0.11 & .28 & .97 & 0.16 & .13 & .97 \\
\hline & $\mathrm{Cz}$ & 0.02 & .88 & .97 & 0.08 & .48 & .97 \\
\hline & $\mathrm{Pz}$ & 0.16 & .13 & .97 & -0.02 & .82 & .97 \\
\hline \multirow[t]{2}{*}{ Beta } & $\mathrm{Fz}$ & 0.03 & .74 & .97 & -0.15 & .16 & .97 \\
\hline & F3 & 0.02 & .87 & .97 & -0.07 & .53 & .97 \\
\hline \multirow{12}{*}{$\begin{array}{l}\text { 节 } \\
0 \\
0 \\
\stackrel{0}{<}\end{array}$} & F4 & -0.03 & .76 & .97 & -0.08 & .46 & .97 \\
\hline & F7 & -0.06 & .54 & .97 & -0.04 & .67 & .97 \\
\hline & F8 & -0.06 & .54 & .97 & -0.07 & .5 & .97 \\
\hline & $\mathrm{Cz}$ & -0.01 & .94 & .97 & 0.09 & .42 & .97 \\
\hline & $\mathrm{Pz}$ & 0.10 & .33 & .97 & -0.03 & .79 & .97 \\
\hline & $\mathrm{Fz}$ & 0.02 & .87 & .97 & -0.04 & .72 & .97 \\
\hline & F3 & -0.01 & .95 & .97 & 0.01 & .94 & .97 \\
\hline & F4 & -0.05 & .64 & .97 & -0.03 & .75 & .97 \\
\hline & F7 & -0.02 & .85 & .97 & 0.00 & .99 & .97 \\
\hline & F8 & -0.14 & .17 & .97 & 0.05 & .62 & .97 \\
\hline & $\mathrm{Cz}$ & -0.04 & .72 & .97 & 0.13 & .22 & .97 \\
\hline & $\mathrm{Pz}$ & 0.14 & .18 & .97 & -0.07 & .51 & .97 \\
\hline \multirow{14}{*}{ 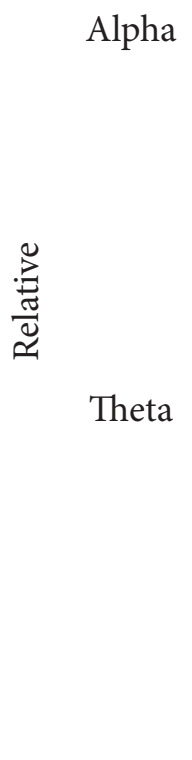 } & $\mathrm{Fz}$ & 0.08 & .47 & .97 & 0.20 & .06 & .29 \\
\hline & F3 & 0.07 & .49 & .97 & 0.12 & .25 & .59 \\
\hline & F4 & 0.10 & .35 & .97 & 0.14 & .2 & .53 \\
\hline & F7 & 0.03 & .79 & .97 & 0.19 & .08 & .32 \\
\hline & F8 & -0.08 & .45 & .97 & 0.22 & .04 & .29 \\
\hline & $\mathrm{Cz}$ & 0.00 & .97 & .97 & 0.06 & .6 & .84 \\
\hline & $\mathrm{Pz}$ & 0.02 & .85 & .97 & 0.05 & .61 & .84 \\
\hline & $\mathrm{Fz}$ & -0.08 & .44 & .97 & -0.22 & .04 & .29 \\
\hline & F3 & -0.05 & .6 & .97 & -0.20 & .06 & .29 \\
\hline & F4 & -0.10 & .35 & .97 & -0.20 & .06 & .29 \\
\hline & F7 & -0.02 & .85 & .97 & -0.21 & .05 & .29 \\
\hline & F8 & -0.06 & .56 & .97 & -0.22 & .04 & .29 \\
\hline & $\mathrm{Cz}$ & -0.01 & .91 & .97 & -0.17 & .1 & .36 \\
\hline & $\mathrm{Pz}$ & 0.04 & .71 & .97 & -0.20 & .06 & .29 \\
\hline
\end{tabular}

Note. $p<.05$ is counted as significant. 
Table 4 presents correlations between the difference scores in band powers and anxiety (math and trait). There were no significant correlations between absolute band power changes and anxiety (math and trait). For math anxiety, no correlations were observed with the relative band power difference score. However, trait anxiety was significantly correlated with difference scores for relative alpha and theta activity for most of the electrodes. To correct for multiple comparisons, we used the FDR-correction (Benjamini \& Hochberg, 1995). After this correction, none of the comparisons reached the level of significance (see Table 4).

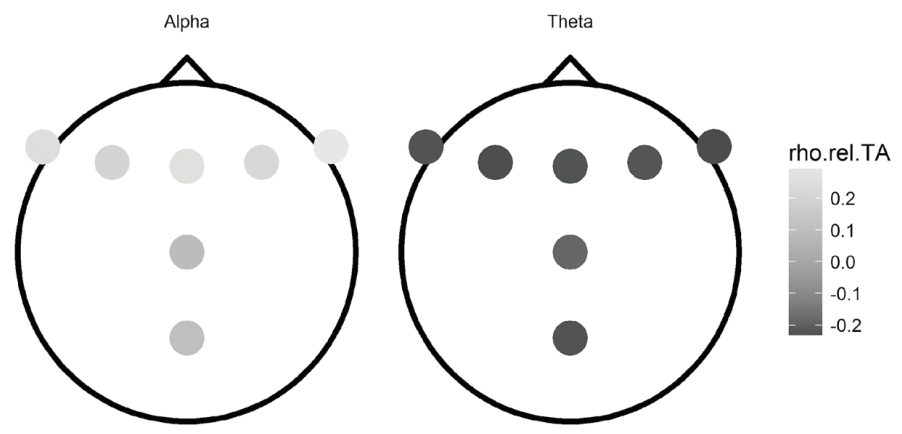

Figure 2. Correlations of power difference score and trait anxiety for alpha and theta relative power

Partial correlations that account for the level of fatigue of a participant at the start of the experiment were not significant for absolute power values. For relative power values, difference scores marginally correlated with trait anxiety at most frontal electrodes in theta band, as well as at the F8 electrode in alpha band (see Figure 2). However, no results reached significance after the FDR-correction (see Table 5).

\section{Discussion}

The aim of this study was to investigate whether the level of mental fatigue during a cognitive task is associated with math and trait anxiety. Mental fatigue was not measured directly. The approach we used in the study was based on the findings which showed that mental fatigue can manifest itself in EEG spectral characteristics at different frequency bands.

We started by exploring differences in EEG spectral power, measured before and after performing math- and language-related cognitive tasks. We analyzed EEG activity in narrow frequency bands together with composite EEG measures (Task Load Index, TLI; and Relative Energy Index, REI). In previous studies, REI was shown to be reversed proportional to energy and related to a state of drowsiness, which is a facet of the state of mental fatigue (Eoh et al., 2005; Lal \& Craig, 2001). Our data did not yield significant differences in REI between the two runs. This result might be explained by a relatively short duration of the experiment (approximately an hour and a half). This relatively short duration, combined with a 5-minute break during the experimental task, may have led to an absence of drowsiness. No significant changes were found in the TLI index. Previous research found 
changes in TLI with an increase of difficulty (Gevins, Smith, McEvoy, \& Yu, 1997). In the present study, the experimental task was not difficult, and the level of difficulty stayed constant throughout the task.

Absolute power in the eyes-closed resting state was higher at run two than at run one in all bands. This is in line with findings by Craig and colleagues (2012). However, the relative power results were not consistent with previous findings (Craig et al., 2012): only theta power increased from run one to run two, while alpha decreased and beta did not show any change. Contrary to our prediction of alpha band power growth with increase of fatigue, as expected from previous research (Craig et al., 2012), relative alpha rhythm decreased in all electrodes except $\mathrm{Pz}$. The existing literature is somewhat inconsistent in establishing the link between alpha activity and fatigue: it was reported to be both decreasing and increasing in different studies (see the review in Craig et al., 2012). In our study, the decrease in relative alpha band activity might be interpreted as a marker of task engagement (Cheng \& Hsu, 2011). Such alertness might be a result of the need for participants to switch between several tasks (arithmetic, lexical, and algebraic) during the session, so that they have to stay vigilant. Overall, our data showed contradictory results for alpha band changes in absolute and relative power approaches.

The data on the link between beta and fatigue are also quite unclear. Craig and colleagues (2012) reported beta increases with fatigue (three studies); decreases with fatigue (one study); and no change (two studies). Our data also show no significant EEG differences before and after performing cognitive tasks. There are different ways to calculate EEG spectral power. Here we used the relative power approach which accounts for all of the spectrum. It is possible that the discrepancies between our study and the aforementioned ones in beta change might be caused by the relative power approach we used. In this approach, more data on EEG activity is used for the calculation of the estimation, so that it might be more accurate and reliable in estimation of power change.

Theta band spectral power differences were consistent for both absolute and relative power approaches. Theta power is considered a robust indicator of fatigue (Craig et al., 2012). In our study theta increased from run one to run two, suggesting mental fatigue in our participants. However, this finding is not consistent with the findings for the other indices. Further research is needed to find a plausible explanation for this contradictory result.

Next, we performed analyses to explore the link between EEG spectral power changes and math and trait anxiety. Given that there were no differences in composite measures across the two runs, and mixed evidence for the beta band (no differences in relative power), we focused on alpha and theta bands in further analysis. Alpha and theta bands showed prominent changes after task performance for both absolute and relative spectral power. However, we found no correlations of absolute EEG activity changes with either anxiety. There were also no correlations between relative activity and math anxiety. Trait anxiety was positively correlated with a decrease in relative alpha and negatively with an increase in relative theta. These correlations failed to reach significance after correction for multiple comparisons. However, the indicated associations may be real, as they were consistent in spatial distribution of the effect (there was similar activity on the adjacent electrodes, see 
Figures 2). The current study may be underpowered to demonstrate these associations robustly.

The positive correlation between the alpha difference score and TA, shown in our study, might be evidence of people with high anxiety having bigger differences between run one and run two; i.e., people with higher TA have lower alpha after the task completion. This might reflect the fact that these people were more engaged with the task, and thus were more vigilant. This result is in line with previous research which showed that lower alpha might be associated with increased focus (Oken, Salinsky, \& Elsas, 2006; Palva \& Palva, 2007). Another interpretation which might be inferred from the partial correlation analysis, is that the alpha band spectral power change is affected by the participant's previous state rather than by his or her level of anxiety during the task. In this case a low level of fatigue before the task might have led to lower fatigue by the end of the task, as compared to people who were fatigued before the recording. In future studies, an independent measurement of initial fatigue level should be taken and controlled for during the analysis.

Our data also showed that there was negative correlation between the theta difference score and TA. A possible explanation for that might be related to the arousal effect of anxiety. For people with high anxiety, participating in the experiment could have stressed them that led to mobilizing their resources, and having less effects of tiredness. Both these findings might be discussed in the framework of the optimal performance theory of Yerkes and Dodson (1908), according to which participants in our study were more vigilant because of their increased anxiety, induced by participation in the experiment. These results are also in line with the results of previous studies, which identified the nonlinear effects of anxiety. For example, one study showed that motivation moderated the relationship between math performance and math anxiety (Wang et al., 2015). The study found that math anxiety might have served as a positive arousal factor for people with high motivation.

Contrary to our initial hypothesis, we failed to find any association between math anxiety and fatigue. This may be interpreted in the context of the motivational control theory of cognitive fatigue (Hockey, 2011). According to that theory, fatigue arises when there exists a conflict between a current and an alternative goal (including rest and biological needs). A person's goals are constantly being evaluated, and when demands for task performance increase, he or she experiences a subjective feeling of discomfort. This leads either to increasing effort, or to leaving the effort unchanged by either sticking to a previous goal despite a deficit in performance, or by switching to another goal. Fatigue arises when a person feels a demand for greater effort, and is expected to dissipate if a person chooses to switch to another task or not to increase his or her effort. One of the predictions of the model discussed by Hockey, is that changing the goal resets the need for effort to normal, thus removing fatigue.

Since MA is considered to be a domain-specific anxiety linked to math performance, in our study there may have been different processes underway during the math-related and lexical tasks of people with high MA. For example, MA may have led to greater arousal during math tasks, preventing a buildup of fatigue. It is not clear whether such a buildup would lead to cancelling out the effects of fatigue experienced during tasks; or whether the tasks on the whole were not long enough 
by themselves to induce fatigue. TA is not specific to any task, and thus there was no goal change for people with high TA. This may explain why the difference scores were linked to the TA level: people with TA might have experienced the whole experiment as one stressful task that continuously sustained their arousal.

\section{Conclusion}

No significant links were found between math and trait anxiety, and mental fatigue. However, some interesting associations were indicated, and need to be explored by a study with better statistical power. Moreover, to better understand the link between math anxiety and mental fatigue, an experiment with only math-related tasks should be designed. Other measures of mental fatigue (e.g. yawning, nodding off, self-reports) should be used to understand the consistency of EEG and other measures of mental fatigue, and to clarify the differential pattern of results for different spectral power bands.

\section{Limitations}

First, the goal switching within the experimental task might not have allowed the tracing of the link between MA and fatigue. Second, the length of the experiment might have affected our findings: although there were some changes in EEG associated with mental fatigue, the length of time of the task might have been insufficient for robustly inducing fatigue. Third, our sample might not have been large enough to detect weak correlations. Previous research reported weak to moderate correlations between trait anxiety and mental fatigue. The link between math anxiety and mental fatigue may be even weaker, and therefore undetectable in our sample. Fourth, mental fatigue was not measured directly.

\section{Acknowledgement}

This work was supported by the Russian Ministry for Education and Science within the project No.25.8663.2017/9.10

\section{References}

Alexander, L. \& Martray, C.R. (1989). The development of an abbreviated version of the Mathematics Anxiety Rating Scale. Measurement and Evaluation in Counseling and Development, 22(3), 143-150. https://doi.org/10.1080/07481756.1989.12022923

Artemenko, C., Daroczy, G., \& Nuerk, H.-C. (2015). Neural correlates of math anxiety-an overview and implications. Frontiers in Psychology, 6, 1333. https://doi.org/10.3389/fpsyg. 2015.01333

Ashcraft, M.H. \& Moore, A.M. (2009). Mathematics Anxiety and the Affective Drop in Performance. Journal of Psychoeducational Assessment, 27(3), 197-205. https://doi.org/10.1177/ 0734282908330580

Benjamini, Y. \& Hochberg, Y. (1995). Controlling the False Discovery Rate: A Practical and Powerful Approach to Multiple Testing. Journal of the Royal Statistical Society. Series B (Methodological). WileyRoyal Statistical Society. https://doi.org/10.2307/2346101 
Bloniewski, T., Likhanov, M., Khuc, J., Budakov, A., Zakharov, I., \& Kovas, Y. (2018). Test-retest reliability of behavioral and ERP measures in math-related processing. The European Proceedings of Social \& Behavioural Sciences. https://dx.doi.org/10.15405/epsbs.2018.11.02.13

Boksem, M.A.S., Meijman, T.F., \& Lorist, M.M. (2005). Mental fatigue, motivation and action monitoring. https://doi.org/10.1016/j.biopsycho.2005.08.007

Boksem, M.A.S. \& Tops, M. (2008). Mental fatigue: Costs and benefits. Brain Research Reviews, 59(1), 125-139. https://doi.org/10.1016/j.brainresrev.2008.07.001

Cantero, J.L., Atienza, M., Salas, R.M., \& Gómez, C.M. (1999). Alpha EEG coherence in different brain states: an electrophysiological index of the arousal level in human subjects. Neuroscience Letters, 271(3), 167-170. https://doi.org/10.1016/S0304-3940(99)00565-0

Carretié, L., Mercado, F., Tapia, M., \& Hinojosa, J.A. (2001). Emotion, attention, and the "negativity bias", studied through event-related potentials. International Journal of Psychophysiology, 41(1), 75-85. https://doi.org/10.1016/S0167-8760(00)00195-1

Cheng, S.-Y. \& Hsu, H.-T. (2011). Mental Fatigue Measurement Using EEG. Risk Management Trends. https://doi.org/10.5772/16376

Craig, A., Tran, Y., Wijesuriya, N., \& Boord, P. (2006). A controlled investigation into the psychological determinants of fatigue. Biological Psychology, 72(1), 78-87. https://doi. org/10.1016/J.BIOPSYCHO.2005.07.005

Craig, A., Tran, Y., Wijesuriya, N., \& Nguyen, H. (2012). Regional brain wave activity changes associated with fatigue. Psychophysiology, 49(4), 574-582. https://doi.org/10.1111/j.14698986.2011.01329.x

Dowker, A., Sarkar, A., \& Looi, C.Y. (2016). Mathematics Anxiety: What Have We Learned in 60 Years? Frontiers in Psychology, 7, 508. https://doi.org/10.3389/fpsyg.2016.00508

Edwards, M.S., Edwards, E.J., \& Lyvers, M. (2017). Cognitive trait anxiety, stress and effort interact to predict inhibitory control. Cognition and Emotion, 31(4), 671-686. https://doi.org/10. 1080/02699931.2016.1152232

Eoh, H.J., Chung, M.K., \& Kim, S.-H. (2005). Electroencephalographic study of drowsiness in simulated driving with sleep deprivation. International Journal of Industrial Ergonomics, 35(4), 307-320. https://doi.org/10.1016/J.ERGON.2004.09.006

Eysenck, M.W. \& Calvo, M.G. (1992). Anxiety and Performance: The Processing Efficiency Theory. Cognition \& Emotion, 6(6), 409-434. https://doi.org/10.1080/02699939208409696

Eysenck, M.W., Derakshan, N., Santos, R., \& Calvo, M.G. (2007). Anxiety and cognitive performance: Attentional control theory. Emotion, 7(2), 336-353. https://doi.org/10.1037/15283542.7.2.336

Gevins, A. \& Smith, M.E. (2003). Neurophysiological measures of cognitive workload during human-computer interaction. Theoretical Issues in Ergonomics Science, 4(1-2), 113-131. https://doi.org/10.1080/14639220210159717

Gevins, A., Smith, M.E., McEvoy, L., \& Yu, D. (1997). High-resolution EEG mapping of cortical activation related to working memory: Effects of task difficulty, type of processing, and practice. Cerebral Cortex, 7(4), 374-385. https://doi.org/10.1093/cercor/7.4.374

Hancock, P.A., Desmond, P.A., \& Matthews, G. (2012). Conceptualizing and defining fatigue. In G. Matthews, P. A. Desmond, C. Neubauer, \& P. A. Hancock (Eds.), The Handbook of Operator Fatigue (pp. 63-73). Burlington: Ashgate Publishing Company.

Hanin, Y.L. \& Spielberger, C.D. (1983). The development and validation of the Russian Form of the State-Trait Anxiety Inventory. Series in Clinical \& Community Psychology: Stress \& Anxiety, 2, 15-26.

Hockey, G.R. J. (2011). A motivational control theory of cognitive fatigue. In P.L. Ackerman (Ed.), Cognitive fatigue: multidisciplinary perspectives on current research and future appli- 
cations (pp. 167-188). Washington, DC: American Psychological Association. https://doi. org/10.1037/12343-008

Jiang, N., Sato, T., Hara, T., Takedomi, Y., Ozaki, I., \& Yamada, S. (2003). Correlations between trait anxiety, personality and fatigue. Journal of Psychosomatic Research, 55(6), 493-500. https://doi.org/10.1016/S0022-3999(03)00021-7

Kamzanova, A.T., Matthews, G., Kustubayeva, A.M., \& Jakupov, S.M. (2011). EEG Indices to Time-On-Task Effects and to a Workload Manipulation (Cueing). International Journal of Psychological and Behavioral Sciences, 5(8), 19-22.

Knyazev, G. (2007). Motivation, emotion, and their inhibitory control mirrored in brain oscillations. Neuroscience \& Biobehavioral Reviews, 31(3), 377-395. https://doi.org/10.1016/j. neubiorev.2006.10.004

Kovas, Y., Galajinsky, E.V., Boivin, M., Harold, G.T., Jones, A., Lemelin, J.-P., ...\& Malykh, S. (2013). The Russian School Twin Registry (RSTR): Project PROGRESS. Twin Research and Human Genetics, 16(1), 126-133. https://doi.org/10.1017/thg.2012.133

Lal, S.K.L. \& Craig, A. (2001). A critical review of the psychophysiology of driver fatigue. Biological Psychology, 55(3), 173-194. https://doi.org/10.1016/S0301-0511(00)00085-5

Likhanov, M., Zakharov, I., Kuzmina, Y., Budakova, A., Vasin, G., Malykh, S., \& Kovas, Y. (2017). Math Anxiety Does Not Moderate the Link between Spatial and Math Ability. The European Proceedings of Social \& Behavioural Science, https://doi.org/10.15405/epsbs.2017.12.21

Lorist, M.M., Klein, M., Nieuwenhuis, S., Jong, R., Mulder, G., \& Meijman, T.F. (2000). Mental fatigue and task control: Planning and preparation. Psychophysiology, 37(5), 614-625. https://doi.org/10.1111/1469-8986.3750614

Matthews, G., Desmond, P.A., \& Hitchcock, E.M. (2012). Dimensional Models of Fatigue. In G. Matthews, P. A. Desmond, C. Neubauer, \& P. A. Hancock (Eds.), The Handbook of Operator Fatigue (pp. 139-154). Burlington: Ashgate Publishing Company.

Núñez-Peña, M.I. \& Suárez-Pellicioni, M. (2014). Less precise representation of numerical magnitude in high math-anxious individuals: An ERP study of the size and distance effects. Biological Psychology, 103, 176-183. https://doi.org/10.1016/j.biopsycho.2014.09.004

Nuwer, M. (1988). Quantitative EEG: I. Techniques and problems of frequency analysis and topographic mapping. Journal of Clinical Neurophysiology: Official Publication of the American Electroencephalographic Society, 5(1), 1-43. https://doi.org/10.1097/00004691-19880100000001

Oken, B.S., Salinsky, M.C., \& Elsas, S.M. (2006). Vigilance, alertness, or sustained attention: physiological basis and measurement. Clinical Neurophysiology, 117(9), 1885-1901. https:// doi.org/10.1016/J.CLINPH.2006.01.017

Palva, S., \& Palva, J.M. (2007). New vistas for a-frequency band oscillations. Trends in Neurosciences, 30(4), 150-158. https://doi.org/10.1016/J.TINS.2007.02.001

Putman, P. (2011). Resting state EEG delta-beta coherence in relation to anxiety, behavioral inhibition, and selective attentional processing of threatening stimuli. International Journal of Psychophysiology, 80(1), 63-68. https://doi.org/10.1016/j.ijpsycho.2011.01.011

Rezaei, F., Hosseini Ramaghani, N.A., \& Fazio, R.L. (2017). The effect of a third-party observer and trait anxiety on neuropsychological performance: the Attentional Control Theory (ACT) perspective. The Clinical Neuropsychologist, 31(3), 632-643. https://doi.org/10.1080 /13854046.2016.1266031

Richardson, F.C. \& Suinn, R.M. (1972). The Mathematics Anxiety Rating Scale: Psychometric data. Journal of Counseling Psychology, 19(6), 551-554. https://doi.org/10.1037/h0033456

Rijsdijk, F.V. \& Sham, P.C. (2002). Analytic approaches to twin data using structural equation models. Briefings in Bioinformatics, 3(2), 119-33. https://doi.org/10.1093/bib/3.2.119 
Santamaria, J. \& Chiappa, K.H. (1987). The EEG of drowsiness in normal adults. Journal of Clinical Neurophysiology: Official Publication of the American Electroencephalographic Society, 4(4), 327-382. https://doi.org/10.1097/00004691-198710000-00002

Spielberger, C.D. (1989). State-Trait Anxiety Inventory: Bibliography (2nd ed.). Palo Alto: CA: Consulting Psychologists Press.

Strijkstra, A.M., Beersma, DG. M., Drayer, B., Halbesma, N., \& Daan, S. (2003). Subjective sleepiness correlates negatively with global alpha $(8-12 \mathrm{~Hz})$ and positively with central frontal theta $(4-8 \mathrm{~Hz})$ frequencies in the human resting awake electroencephalogram. Neuroscience Letters, 340(1), 17-20. https://doi.org/10.1016/S0304-3940(03)00033-8

Suárez-Pellicioni, M., Núñez-Peña, M.I., \& Colomé, À. (2016). Math anxiety: A review of its cognitive consequences, psychophysiological correlates, and brain bases. Cognitive, Affective, \& Behavioral Neuroscience, 16(1), 3-22. https://doi.org/10.3758/s13415-015-0370-7

Wang, X., Huang, Y., Ma, Q., \& Li, N. (2012). Event-related potential P2 correlates of implicit aesthetic experience. Neuroreport, 23(14), 862-866. https://doi.org/10.1097/WNR. ob013e3283587161

Wang, Z., Lukowski, S.L., Hart, S. A., Lyons, I.M., Thompson, L.A., Kovas, Y., ...\& Petrill, S.A. (2015). Is Math Anxiety Always Bad for Math Learning? The Role of Math Motivation. Psychological Science. 26(12), 1863-1876. https://doi.org/10.1177/0956797615602471

Wascher, E., Rasch, B., Sänger, J., Hoffmann, S., Schneider, D., Rinkenauer, G., ...\& Gutberlet, I. (2014). Frontal theta activity reflects distinct aspects of mental fatigue. Biological Psycho$\log y$, 96, 57-65. https://doi.org/10.1016/j.biopsycho.2013.11.010

Wijesuriya, N., Tran, Y., \& Craig, A. (2007). The psychophysiological determinants of fatigue. International Journal of Psychophysiology, 63(1), 77-86. https://doi.org/10.1016/j.ijpsycho. 2006.08.005

Yerkes, R.M. \& Dodson, J.D. (1908). The relation of strength of stimulus to rapidity of habitformation. Journal of Comparative Neurology and Psychology, 18(5), 459-482. https://doi. org/10.1002/cne.920180503 